Bioscientia Medicina: Journal of Biomedicine \& Translational Research

Journal Homepage: www.bioscmed.com

\title{
Difference between Hypertrophic Pyloric Stenosis in Child with History of Prematurity and Aterm
}

\section{Farid I Hussein ${ }^{*}$, Yusri Dianne Jurnalis ${ }^{1}$}

${ }^{1}$ Faculty of Medicine, Andalas University, Padang, Indonesia

\author{
A R T I C L E I N F O \\ Keywords: \\ Children \\ Hypertrophic pyloric stenosis \\ Pyloromyotomy \\ *Corresponding author: \\ Farid I Hussein \\ E-mail address: \\ faridihussein@gmail.com
}

All authors have reviewed and approved the final version of the manuscript.

https://doi.org/10.37275/bsm.v6i3.463

\begin{abstract}
A B S T R A C T
Background. Hypertrophic pyloric stenosis (HPS) is an acquired condition in which the circumferential muscle of the pyloric sphincter becomes thickened, resulting in elongation and obliteration of the pyloric channel. HPS is the most common gastrointestinal disease in the first few weeks of life. Case presentation: Two patient: a girl, 2 month old (aterm baby) and a boy, 2 months old (preterm baby) with diagnosis moderate dehydration ec vomiting, suspect HPS. Both patient got recurrent vomiting since 1 week before admission, and got dehydration, The vomiting was projectile, occuring after the patient was drink the formula milk. We found the olive sign in both patients, but it was not an obligation we should find olive sign, because it just found in $70 \%$ patients of HPS. In these patients were found sunken eyes, and slow return turgor that indicating dehydration. Patients were got Ultrasonography and planned for barium meal examination and $\mathrm{Ph}$ monitoring. These patients was undergone pyloromyotomi for definite therapy. After surgery preterm baby was still vomiting for 2-3 days in preterm baby, but not in aterm baby. Conclusion: HPS in preterm baby got more complications after surgery than aterm baby, such as: longer length of stay, reflux post operative.
\end{abstract}

\section{Introduction}

Hypertrophic pyloric stenosis (HPS) is an acquired condition in which the circumferential muscle of the pyloric sphincter becomes thickened, resulting in elongation and obliteration of the pyloric channel. ${ }^{1} \mathrm{HPS}$ is the most common gastrointestinal disease in the first few weeks of life. HPS refers to a pylorus that is narrow. HPS is the most common cause of gastric outlet obstruction in infants resulting in nonbilious vomiting. It is more common in boys than girls $(2: 1) .^{2}$ But, in the other research, the male to female ratio is about $4: 1$. It is occurring at the age of 2-8 weeks. It has an incidence of 3 per 1,000 live births per year, although wide variations have been documented with geographic location, season and ethnic origin. This disease usually presents between the second and sixth weeks of life. ${ }^{3}$ Incident of HPS in Indonesia remained unclear, but in RSUP DR M Djamil, there's only 6 case in period of 2016-2020. The clinical presentation is projectile and non-billious vomiting. Hypertrophic Pyloric stenosis is due to congenital hypertrophy of the pyloric sphincter. The lumen of the pylorus is narrower, and less food is able to pass through. 4,5

In 1907, although this curious disease is treated easily with surgery, its etiology remains undetermined. The exact etiology of the condition is unknown, but it carries a multifactorial pattern (environmental and genetic). The most common risk factors are family history, gender, younger maternal age, being a first 
born infant, and pattern of feeding. ${ }^{6-8}$

There are many modalities to help make the diagnosis. Radiologists have been using ultrasound (US) to investigate HPS since 1977, and it is the reference standard for diagnosis. The other modalities to help the diagnosis is the barium meal, but have some weakness. Barium meal examination only perform if the USG can't help the HPS diagnosis.9

Pyloromyotomy remains the standard of treatment, and outcome is excellent. The best surgical outcome and lowest complications are more likely when the surgeon has specialist pediatric surgical training. Pyloromyotomy can be performed by open or Endoscopic. Endoscopic pyloromyotomy is a simple procedure and can be performed as an outpatient procedure. Recently, endoscopic balloon dilatation of hypertrophic pyloric stenosis after failed pyloromyotomy has been used with greater frequency. $.5,10$ The purpose of this case presentation to report a case of Hypertrophic pyloric stenosis from two patients, first patient with aterm baby, another patient with preterm baby, onset of HPS in both patient is same, in the fifth week of life.

\section{Case Presentation}

\section{Case 1}

Baby YS, a 2 month old girl baby was hospitalized in Dr. M Djamil Hospital pediatric ward for 15 days with chief complain recurrent vomiting since 1 week ago, frequency 5-7 times/day, 4-5 spoon/times contains formula milk, projectile, vomiting usually present after drink a milk. Last vomit was 4 hours ago, colour was white contained formula milk and breast milk, and projectile. The patient got breast milk on demand plus formula milk every 2-3 hour, amount $\pm 60 \mathrm{cc} /$ times. The stomach looked distended since 1 week ago. There was no diarrhea and bloody stool before, there is no defecation in last 3 days. Patient looked thirsty, micturition was dark and less, last 3 hours ago. Patient was admitted in $\mathrm{M}$ Djamil Hospital by Pediatric department with observation vomitus and fasting temporary. Patient was consulted to Surgery Department and treat together with diagnosis Suspected Hypertrophic Pyloric stenosis. Patient was planned for supine and LLD abdominal $\mathrm{x}$ ray, and Abdominal ultrasonography. Patient was second child, born with sectio caesarean delivery due to high risk mother, aterm baby birth weight was 3100 gram, birth length was $48 \mathrm{~cm}$, vigorous baby.
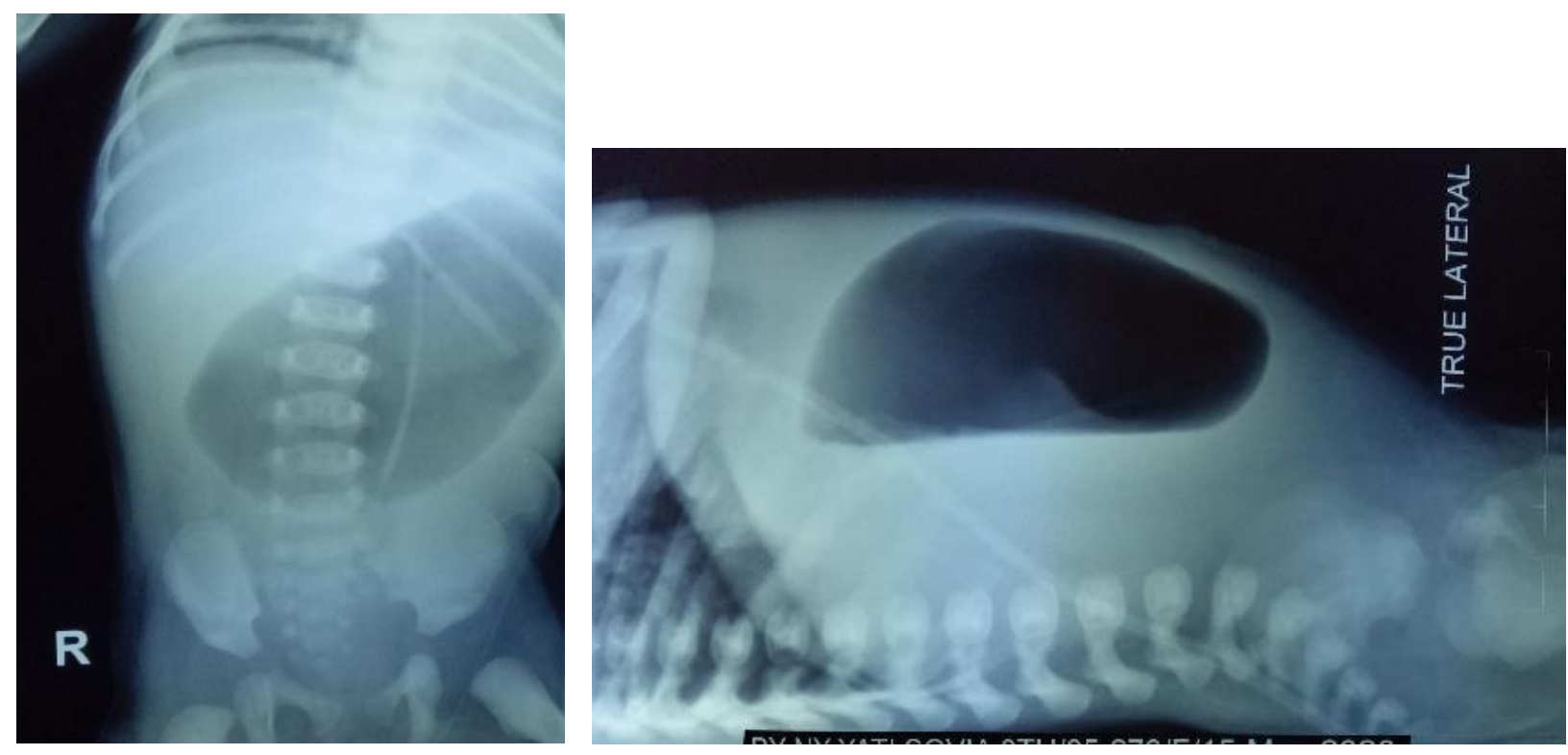

Figure 1. Abdominal X-Ray 2 position 


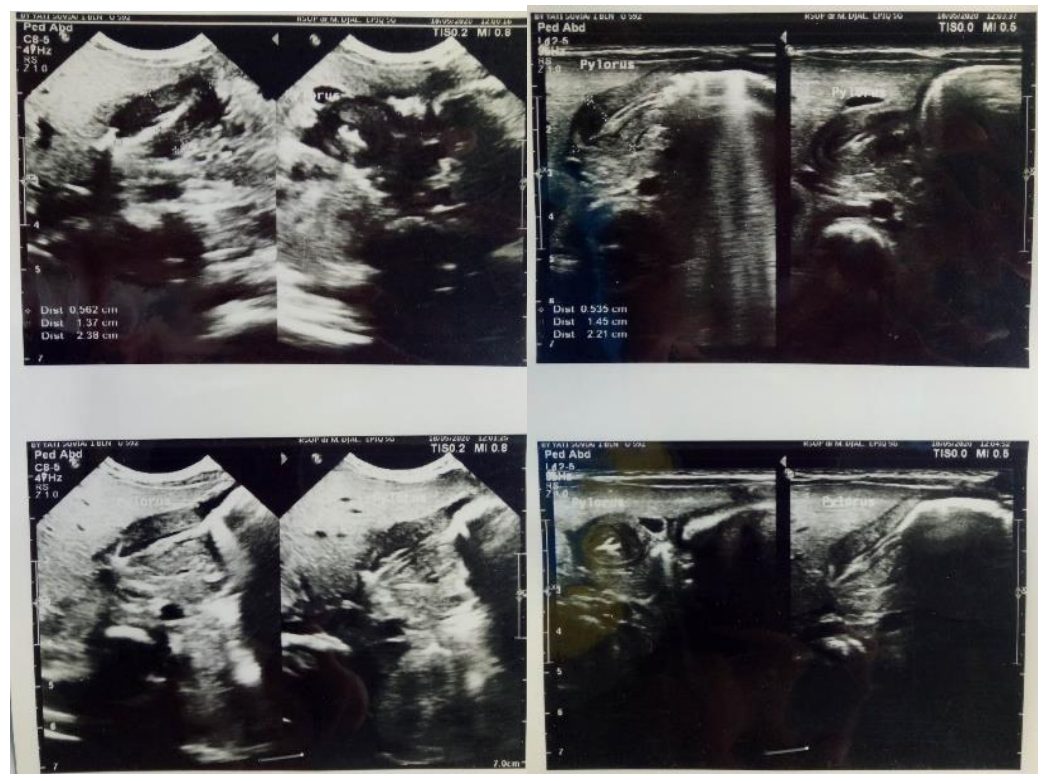

Figure 2. Abdominal ultrasonography

Patient looks moderately ill, heart rate 150 times per minute, respiratory rate 30 times per minute, body temperature $37{ }^{\circ} \mathrm{C}$, body weight $3.100 \mathrm{gr}$, body weight before sick was 3.400gr, rehydrated body weight was $3290 \mathrm{gr}$, body height $49 \mathrm{~cm}$, weight for age was $-2 \mathrm{SD}$ $\leq Z \leq 0$ SD Score, length for age was $-2 \mathrm{SD} \leq Z$ Score $\leq 0 \mathrm{SD}$, weight for height was $0 \mathrm{SD} \leq Z$ Score $\leq+2 \mathrm{SD}$, impression well nourished. There was no anemic nor edema, no jaundice and cyanotic. Skin was warm, turgor was slowly returned. There was no regional lymph enlargement. Head was round and symmetric, head circumference $39 \mathrm{~cm}$ (normal based on Nellhauss standard), depressed fontanella. There was sunken eyes, conjunctiva was not anemic, sclera was not icteric, pupil isochors with diameter $2 \mathrm{~mm} / 2 \mathrm{~mm}$, light reflex was positive normal. Ears and nose were normal. Tonsil was T1-T1, not hyperemic and pharynx was not hyperemic. Mouth's mucous was dry. The chest was symmetric, no retraction, lung sound: bronchovesicular, no rales, no wheezing, heart: ictus was palpable at left midclavicularis line, intercostal space V, heart sound: regular rhythm, no murmur. There was no abdominal distension, liver was palpable 1/4-1/4, sharp edge, homogenous, spleen was not palpable, olive sign $(+)$, peristaltic sound was normal, turgor slowly returned. No abnormality found in genitalia, puberty state $\mathrm{A}_{1} \mathrm{P}_{1} \mathrm{G}_{1}$. Extremities was warm with good perfusion, physiological reflexes were positive normal.

Haemoglobin $11 \mathrm{~g} / \mathrm{dL}$, white blood cell 9.270/ $\mathrm{mm}^{3}$, differential count $0 / 0 / 0 / 67 / 26 / 7$, hematocrite 33 vol\%, platelets $539.000 / \mathrm{mm}^{3}$, Sodium $133 \mathrm{mmol} / \mathrm{L}$, Potassium 3,2 mmol/L blood glucose $110 \mathrm{mg} / \mathrm{dl}$.

Patient was performed pyloromyotomy, still fasting temporary. Patient was using 2 nasogastric tube, NGT 1: connecting into gaster, NGT 2: connecting into pylorus, there's no vomit, no fever mixturition and defecation in normal limit. After surgery patient got Total Parenteral Nutrition IVFD D12,5\% with electrolyte $20 \mathrm{gtt} /$ minute (micro), Aminofusin ped 5\% $100 \mathrm{cc} /$ day, Ivelip 20\% 15cc/day, then try Intake per NGT (into duodenum) increased gradually from $12 \mathrm{x}$ 10cc until full feed 12 x $30 \mathrm{cc}$. in the next day Patient tried to got breast milk, $8 \times 40 \mathrm{cc}$ per NGT, after patient got full feed, NGT was taken out, then patient tried to feed per orally, increased gradually, no fever, no vomit, micturition and defecation was in normal limit, and patient was discharge in $14^{\text {th }}$ day of hospitalization.

\section{Case 2}

Baby FO, a 2 month old boy baby was hospitalized in Dr. M Djamil Hospital pediatric ward for 16 days with chief complain recurrent vomiting since 2 week ago, increased more frequently in this 1 week, frequency 510 times/day, 3-5 spoon/times contains with formula milk and yellowish liquid, sometimes projectile, 
vomiting usually present after drink a milk. Last vomit was 4 hours ago, colour was white contained breast milk, and sometimes projectile. The patient got formula and breast milk, but in last 4 days formula milk was not given. The stomach looked distended since 1 week ago. There's no defecation in last 5 days.There is no fever. Bodyweight loss since illness, from 3,2 kg to 2,9 kg. patient got breastmilk, sometimes was given formula milk, but since 4 days ago, patient just got breastmilk. There was no history of diarrhea and bloody stool before. Patient was looked thirsty, micturition was dark and less in last 1 day. Patient was referred from private hospital with Susp Hypertrofic Pyloric Stenosis, patient had been performed Abdominal X-ray with conclusion: Dilated gaster due to pyloric obstruction due to susp. HPS DD volvulus and had been performed abdominal ultrasonography with conclusion: suggestive HPS. Patient was consulted to Surgery Department and treat together with diagnosis Suspected Hypertrophic Pyloric stenosis. Patient was second child, lowbirth bodyweight neonates with sectio caesarean delivery due to history of former sectio caesarean delivery with lowbirth bodyweight 2200 gram and birth length $46 \mathrm{~cm}$, vigorous, preterm baby.

Patient looks moderately ill, heart rate 152 times per minute, respiratory rate 30 times per minute, body temperature $36,7{ }^{\circ} \mathrm{C}$, body weight $2.750 \mathrm{gr}$, bodyweight before sick was 3.000 gr, rehydrated bodyweight 2.915 gr, body height $50 \mathrm{~cm}$, weight for age was $-3 \mathrm{SD} \leq Z \leq$
$-2 \mathrm{SD}$ Score, length for age was $-2 \mathrm{SD} \leq Z$ Score $\leq 0$ $\mathrm{SD}$, weight for height was $-3 \mathrm{SD} \leq \mathrm{Z}$ Score $\leq-2 \mathrm{SD}$, impression undernourished. There was no anemic nor edema, no jaundice and cyanotic. Skin was warm, turgor was slowly returned. There was no regional lymph enlargement. Head was round and symmetric, head circumference $35 \mathrm{~cm}$ (normal based on Nellhauss standard), depressed fontanella, sunken eyes was present, conjunctiva was not anemic, sclera was not icteric, pupil isochors with diameter $2 \mathrm{~mm} / 2 \mathrm{~mm}$, light reflex was positive normal. Ears and nose were normal. Tonsil was T1-T1, not hyperemic and pharynx was not hyperemic. Mouth's mucous was dry. The chest was symmetric, no retraction, lung: bronchovesicular, no rales, no wheezing, heart: ictus was palpable at left midclavicularis line, intercostal space V, heart sound: regular rhythm, no murmur. There were no abdominal distension, liver was palpable 1/4-1/4, sharp margin, homogenous, and the spleen was not palpable, olive sign $(+)$, peristaltic sound was normal, turgor was slowly returned. No abnormality found in genitalia, puberty state $A_{1} P_{1} G_{1}$. Extremities was warm with good perfusion, physiological reflexes were positive normal, laboratory result was Haemoglobin $12 \mathrm{~g} / \mathrm{dL}$, white blood cell $6.090 / \mathrm{mm} 3$, differential count 0/1/1/17/70/11, hematocrite 33 vol\%, platelets $581.000 / \mathrm{mm}$, Sodium $135 \mathrm{mmol} / \mathrm{L}$, Potassium 2,7 $\mathrm{mmol} / \mathrm{L}$ blood glucose $121 \mathrm{mg} / \mathrm{dl}$.

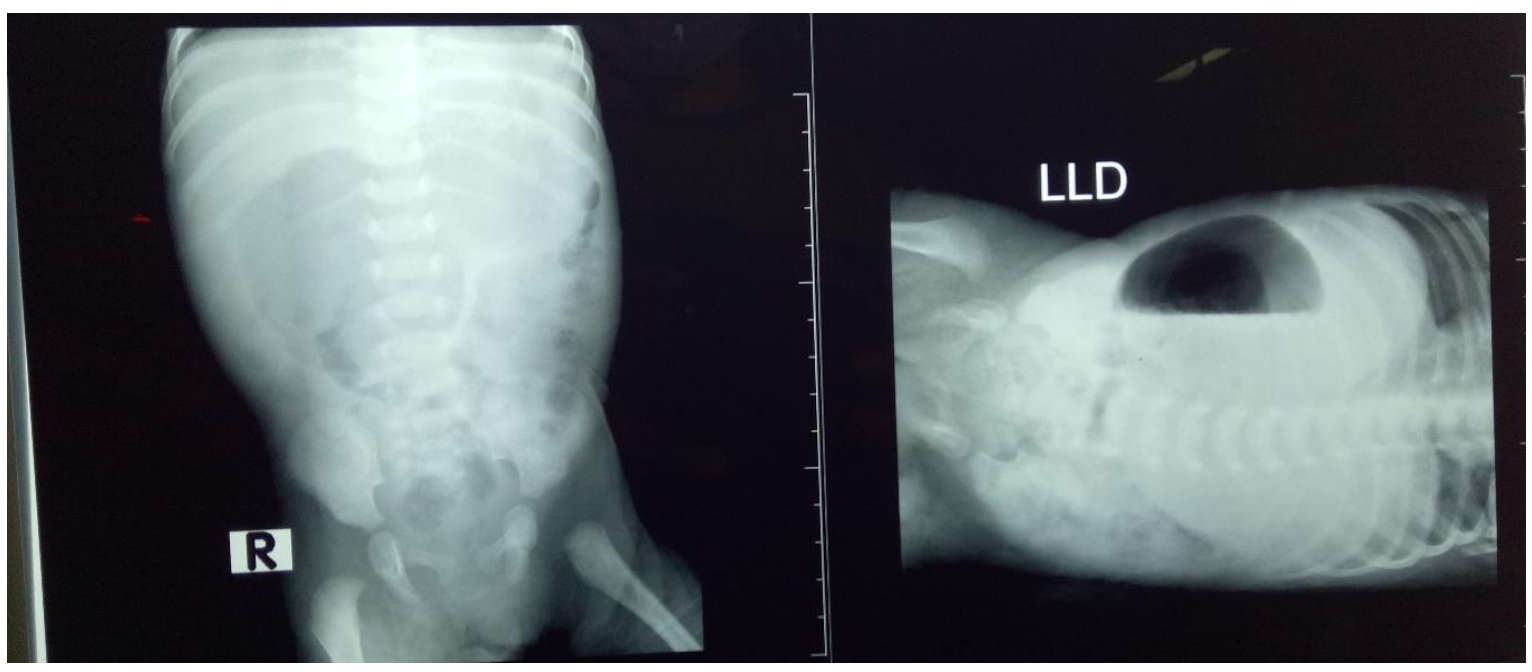

Figure 3. Abdominal X-Ray 2 position 


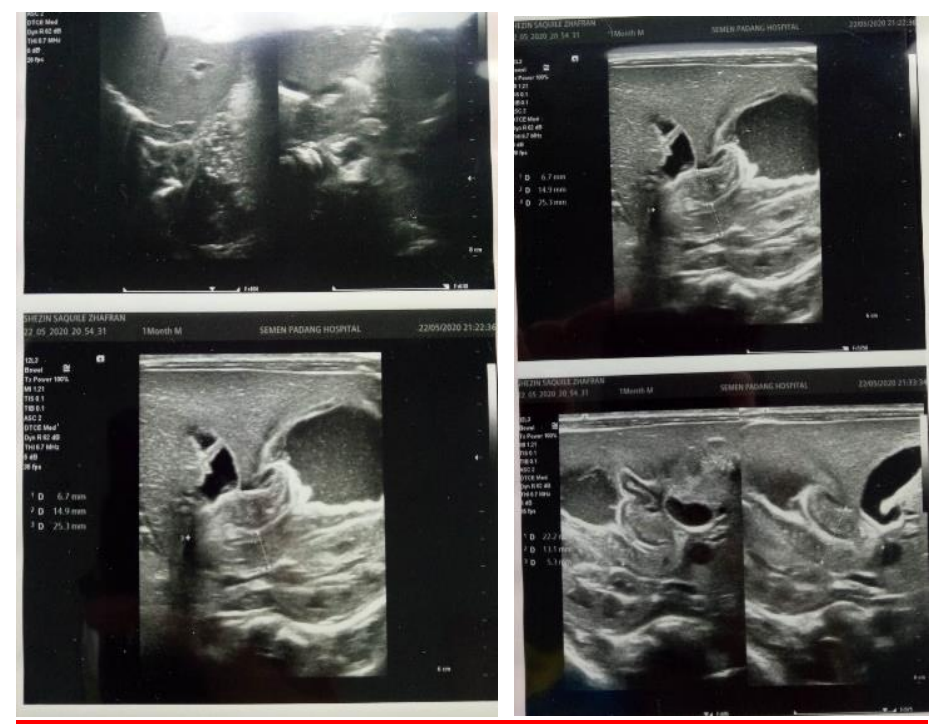

Figure 4. Abdominal ultrasonography

Patient was performed pyloromyotomy and got Central Venous Catheter because perifer line was difficult to access. still fasting temporary. Patient was using 2 nasogastric tube, NGT 1: connecting into gaster, NGT 2: connecting into pylorus, there's no vomit, no fever, mixturition was in normal limit. Patient tried to get intake per NGT duodenum, but residual fluid still exist for 2 days about \pm 5-10cc/day. Laboratory resut after surgery was Haemoglobin 9,5 $\mathrm{g} / \mathrm{dL}$, white blood cell $7.050 / \mathrm{mm} 3$, differential count 0/0/3/65/28/3, hematocrite 29 vol\%, eritrocyte 3.290.000, platelets 304.000/mm3, MCV 85 MCH 29 MCHC 34, Sodium: $132 \mathrm{mmol} / \mathrm{L}$, Potassium: 4,1 mmol/L, Calcium 9,8mg/dL, Albumin 3,5mg/dL, blood glucose: $130 \mathrm{mg} / \mathrm{dl}$. After surgery patient got Total Parenteral Nutrition IVFD D12,5\% with electrolyte 20 $\mathrm{gtt} / \mathrm{minute}$ (micro), Aminofusin ped 5\% 100cc/day, Ivelip 20\% 15cc/day, then try Intake per NGT (into duodenum) increased gradually from 12 x 10cc until full feed 12 x $30 \mathrm{cc}$, Transfussion PRC 1 x 30cc, add antibiotic Ampicillin 4x150 mg iv post operation, paracetamol $4 \times 50 \mathrm{mg}$ iv. Then patient was given breast milk per NGT, $12 \times 30 \mathrm{cc}$, defecation was in normal limit, both NGT had been taken out, after that patient tried to take intake per orally, there's no residue, no vomiting, no fever, ad patient was discharge in $16^{\text {th }}$ day of hospitalization.

\section{Discussion}

In HPS, the pyloric portion of the stomach becomes abnormally thickened, resulting in narrowing and elongation of the pyloric channel. A gastric outlet obstruction is produced, with compensatory dilation, hypertrophy, and hyperperistalsis of the stomach. Most infants with HPS present in the first 2 to 12 weeks of life with forceful or projectile nonbilious vomiting after feeding.15 The emesis may become blood-tinged because of gastritis. The timing of the presentation is likely related to increasing volumes of enteral feeding acting on abnormal pyloric tissue. Many infants with HPS are initially believed to have a food allergy or gastroesophageal reflux. The narrow window of diagnosis between approximately 2 and 12 weeks may be due to the introduction of enteral feeding, which acts on abnormal pyloric tissue. $5,8,16$

Prevalence of HPS estimates are in the range of 1 of 3 per 1,000 live births per year, although wide variations have been documented with geographic location, season and ethnic origin.3 HPS prevalence varies by maternal race/ethnicity. Studies in the United States generally report higher prevalence of HPS among white non-Hispanic mothers, with significantly lower prevalence among non hispanic black mothers.

Because HPS presents with symptoms that resemblethose associated with other gastrointestinal disturbances, such as gastroesophageal reflux disease (GERD), it can be misdiagnosed in its early stages.18, 
19 Once it is identified, however, surgical correction by pyloromyotomy is considered curative, with a very low mortality rate (ie, $0.1 \%$ ) and incidence recurrence in only $1 \%$ of patients. Typically, treated infants recover quickly and can begin feeding within hours after surgery. The clinical pathway to diagnose the HPS was shown in figure 1.5,6

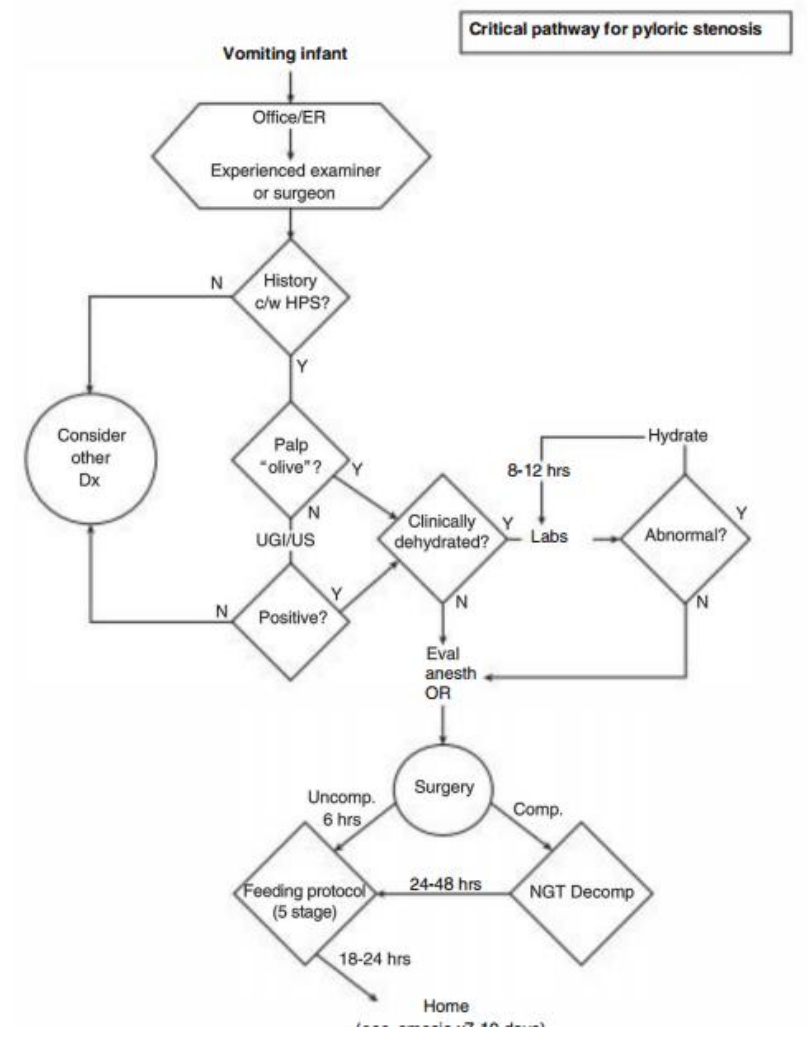

Figure 5. Clinical pathway hypertrophic pyloric stenosis

Although the etiology of HPS remains unknown, providers can quickly recognize the signs and symptoms of HPS in order for surgical treatment to be scheduled in a timely manner. The diagnosis is primarily made by history and physical exam. Infants treated with the Macrolide erythromycin during the first two weeks after birth are at increased risk of HPS. 20 History of Macrolide antibiotics uses for upper and lower respiratory tract infections must be noticed. ${ }^{21}$ The classic clinical presentation of pyloric stenosis is projectile nonbilious vomiting in an infant 3 to 6 weeks of age. Although the disease rarely presents at birth, some infants will develop a crescendo pattern of emesis that begins in the first week of life and progresses to full presentation as late as 3 to 4 months of age. Significant metabolic alkalosis and malnutrition may occur as a consequence of prolonged symptoms.7,16,22

The typical physical exam findings in these patients include visible peristaltic waves in the epigastrium and the presence of a palpable mass in the upper abdomen. The mass or "olive" may be distinguished by an experienced examiner in $70 \%$ to $90 \%$ of patients. Identification of this finding often requires gastric decompression and a cooperative patient. The infant is most easily examined in the supine position with either a pacifier or bottle of sugar water given to keep him or her calm. The legs are gently elevated to relax the abdominal wall musculature and the abdomen is palpated in the subxiphoid region about one half the distance to the umbilicus. The examiner must be patient and occasionally must return to reexamine the infant in order to identify the "olive' In the absence of a palpable mass, an upper gastrointestinal (UGI) contrast study or ultrasonographic evaluation will usually make the diagnosis. ${ }^{6}$ The initial physical exam should also include an assessment of the patient's overall clinical status and degree of dehydration. $3,5,131$ 
In most pediatric centers, the study of choice is an abdominal ultrasound (US). The ultrasonographic criteria for pyloric stenosis include a pyloric channel length $>17 \mathrm{~mm}$, pyloric muscle diameter $>14 \mathrm{~mm}$, and pyloric muscle wall thickness $>4 \mathrm{~mm}$. This technique is reliable and decreases the risk of aspiration. If the US is incon clusive or there is concern for gastroesophageal reflux, malrotation, or anatomic anoma-lies, then an
UGI series should be performed. This study will demonstrate the presence of a distended stomach with narrowing and elongation of the pyloric channel-the "string" sign or "double track" sign. Other findings seen on UGI series include "shoulders" at the proximal end of the pylorus reflecting the hypertrophied muscle bulging into the gastric lumen.9,23
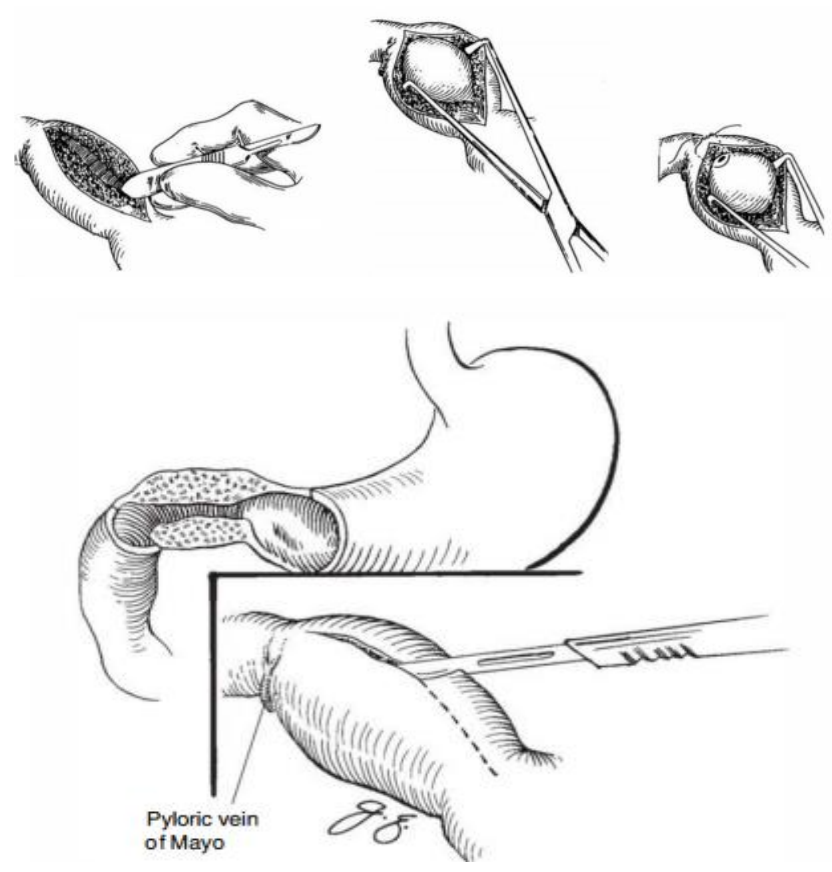

Figure 6. Pyloromyotomy

\section{Treatment}

Initial management of vomiting in children should begin with fluid replacement if the patient appears dehydrated or if lab findings suggest an electrolyte imbalance. ${ }^{24}$ If HPS is suspected, a pediatric surgery consult should be obtained. Surgical correction by a pyloromyotomy is curative. Presurgical gastric decompression via nasogastric tube placement will reduce the risk for postoperative vomiting and gastritis. $^{2}$

\section{Medical treatment}

Medical treatment for HPS was giving of Atropin oral or intravenous administrtion.23,25 The dosage of Aropin intravenous was $0,01 \mathrm{mg} / \mathrm{bw} /$ day divide to six dosage, and continue to oral if there is not contraindication. ${ }^{26}$ Study in 2013 at Saudi Arabia show the effectivity of atropin for HPS> Atropin dosage was $0,1 \mathrm{mg} / \mathrm{bw} /$ days divide to six intravenous give before meal, continue with $0,02 \mathrm{mg} / \mathrm{kg} /$ day divide to 6 dosage oral if there no contraindication. USG Evaluation of this treatment show reduce of muscle thickness. The side effect of aropin was flusing, tachycardia and increase of liver enzyme. ${ }^{23}$

The laparoscopic approach, first described in the literature in the mid-1990s, is gaining popularity among surgeons, although recent studies have demonstrated that open and laparoscopic procedures are comparably safe and effective for the management of HPS. ${ }^{29}$ Jia et al indicate that the laparoscopic approach results in reduced postoperative emesis, shorter length of hospital stay, and shorter recovery times; Hall et al emphasize the advantages of laparoscopic pyloromyotomy and recommend it over open surgery in facilities with experienced surgeons. ${ }^{10,30}$ 


\section{Complication}

Pyloromyotomy is associated with a low incidence of morbidity and mortality. A retrospective review of a large number of patients from 2 pediatric surgical centers between 1969 and 1994 revealed a 10\% overall complication rate. Over the 25-year period, 901 infants underwent pyloromyotomy via a right upper quadrant incision. Intraoperative complications occurred in $4 \%$ of patients (39 duodenal perforations, 1 difficult intubation). Postoperative complications occurred in $6 \%$ (1\% wound infection, $3.5 \%$ postoperative vomiting beyond 48 hours, and 1 death from delayed diagnosis of Hirschsprung's disease and enterocolitis). There were no incomplete pyloromyotomies. ${ }^{31}$

The frequency of associated reflux in infants with treated HPS may be in the range of $10 \%$ to $15 \%$. Antireflux measures and medications usually control the symptoms. Those patients who are refractory to medical therapy or have persistent projectile nonbilious emesis beyond 10 days should be suspected of having an inadequate myotomy. This is a very rare complication but tends to occur in the setting of inadequate proximal extension of the myotomy onto the gastric antrum. Diagnostic imaging studies are typically not useful because the radiographic findings of HPS may persist for many weeks to months postoperatively, despite the resolution of symptoms. the incidence of infectious (pneumonia/septicemia) and metabolic (shock/convulsions) complications was as high as $30 \%$ to $40 \%$ and mortality rates approached $20 \% .^{27}$

\section{Prognosis}

Earlier diagnosis, improved preoperative management, better anesthetic care, and an overall enhanced understanding of the pathophysiology of the disease have led to a precipitous decline in the morbidity and mortality for surgery to less than $10 \%$ and $0.5 \%$, respectively. Currently, most uncomplicated patients may be discharged within 24 hours of surgery. Minor episodes of emesis or "wet burps" may persist for up to 2 weeks postoperatively. Most patients will have a rapid and complete resolution of vomiting by 1 week following their procedure. The hypertrophied muscle retains to normal caliber at about 3 to 4 weeks after surgery. There appear to be no major long-term residua in patients who have had surgery for HPS. 30

This patient was undergo pyloromyotomi for definite therapy. The preferred treatment for HPS is surgical intervention. Surgical correction has been so consistently successful that the treatment of choice for HPS is the Ramstedt pyloromyotomy. It has been the standard treatment of HPS for decades. Although the approach may differ based on the individual surgeon's preference, the pyloric muscle is pulled through an incision in the abdominal wall. A longitudinal incision is made through the muscle with blunt dissection to the submucosa on the anterior surface of the pylorus. The pylorus is then returned to the abdominal cavity, and the abdominal incision is sutured. Most patients have excellent short-term and long-term outcomes. and mortality has been virtually eliminated with the use of appropriate fluid resuscitation, improvements in anesthesia, and a standard surgical approach. Muscle thickness returns to normal within 4 weeks, and is associated with heal-ing of the pyloric muscle and return of function. ${ }^{5}$ when premature baby got pyloromyotomy, baby will get increased risk of postoperative LOS and it suited with the references. ${ }^{33}$

After surgery patients was still vomiting for 2-3 days in preterm baby, but not in aterm baby. After that patient was gain condition and tolerate breast milk. Although $30 \%$ to $90 \%$ of patients will have some degree of postoperative emesis, this typically resolves spontaneously within the first week. The frequency of associated reflux in infants with treated HPS may be in the range of $10 \%$ to $15 \%$. Antireflux measures and medications usually control the symptoms. Those patients who are refractory to medical therapy or have persistent projectile nonbilious emesis beyond 10 days should be suspected of having an inadequate myotomy.2,3,25 Preterm baby got postperative PRC tranfussion, while the aterm baby didn't get any transfussion, it is not suited with any references, because aterm baby had higher risk to transfussion postoperative, there was no explanation about this, because it was just epidemiologic data. 33 


\section{Conclusion}

HPS in preterm baby got more complications after surgery than aterm baby, such as: longer length of stay, reflux post operative.

\section{References}

1. Falcone Jr RA. Pyloric stenosis, hypertrophic. Pediatric Clinical Advisor. Elsevier. 2007; 475.

2. Harken AH and Moore EE. Abernathy's surgical secrets e-book. Elsevier Health Sciences. 2017.

3. Torrão H. Hypertrophic pyloric stenosis: Tips and tricks for ultrasound diagnosis. 2012.

4. Feng $Z$, Nie $Y$, Zhang $Y$, Li Q, Xia H, Gong S, et al. The clinical features of infantile hypertrophyc pyloric stenosis in chinese han population: analysis from 1998 to 2010 Plos One. 2014; 9: 1-6.

5. Schwartz. Hypertrophic pyloric stenosis in: Pediatric surgery 7th Ed. Elsevier Saunders; 2012; 1: 1020-31.

6. Barksdale E. Ponsky TA. Pyloric Stenosis in: Operative Pediatric surgery 2nd Ed. Mcgraw Hill Education; 2014; 534-39.

7. Sveningssona A. Genetic and epidemiological studies of infantile hypertrophic pyloric stenosis. Karolinska institute. 2011; 45: 3132.

8. Troebs RB. Pathophysiology of hypertrophic pyloric stenosis revisited: The use of isotonic fluid for preoperative infusion therapy is supported. Open Journal of Pediatrics; 4: 20815.

9. Eberly MD, Eide MB, Thopmson JL, Nylund CM. Azithromycin in early infancy and pyloric stenosis. Pediatrics. 2015; 135(3): 483-88.

10. Kamsakul W, Cannon ML, Gillespie S, Vaughan R. Idiopathic non hypertrophic pyloric stenosis in an infant succesfully treated via endoscopic approach. World J Gastrointest Endosc.2010; 2(12): 413-6.

11. Burdan F, Rozylo-Kalinowska I, Szumilo J, et al. Anatomical classification of the shape and topography of the stomach. Surgical and radiologic anatomy. 2012; 34: 171-8.

12. Sola JE, Neville HL. Laparoscopic vs open pyloromyotomy: A systematic review and metaanalysis. J Pediatr Surg 2009; 44(8): 1631-7.

13. Guyton A, Hall J. Propulsion and mixing of food in the alimentary tract. Textbook of Medical Physiology eleventh ed. Elsevier Saunders.2006: 781-80.

14. Mayoof AF, Doghan IK. Late onset infantile hypertrophic pyloric stenosis. J Ped Surg. Case Reports. 2017; 30: 22-4.

15. Dessanti A, Migaleddu, Castiglia P, Grandi N. Infantile hypertrophic pyloric stenosis surgery versus nutritional therapy. J Pediatr Neonatal Care. 2016; 4: 1-6.

16. Rogers IM. New Insights on the Patoghenesis of Pyloric stenois of infancy. A review with emphasis on the hyperacidity theory. Open Journal of Pediatrcs. 2012; 97-105.

17. Hernanz-Schulman. Infantile Hypertrophic Pyloric Stenosis. Radiology. 2003. 319-31.

18. Jia WQ, Tian JH, Yang KH, Ma B, Liu YL, Zhang $\mathrm{P}$, et al. Open versus laparoscopic pyloromyotomy for pyloric stenosis: a metaanalysis of randomized controlled trials. European Journal of Pediatric Surgery 2011; 21(2): 77-81.

19. Ranells JD, Carver JD, Kirby RS. Infantile Hypertrophic Pyloric Stenosis: Epidemiology, Genetics, and Clinical Update. Adv in Ped. 2011; 58: 195-206.

20. Koda YK, Ozaki MJ, Murasca K, Vidolin E. Clinical features and prevalence of gastroesophageal reflux disease in infants attending a pediatric gastroenterology reference service. Arq Gastroenterol. 2010; 47: 66-71.

21. Vandenplas. Pediatric gastroesophageal reflux clinical practice guidelines: Joint recommendations of the North American society of pediatric gastroenterology, hepatology, and nutrition and the European Society of Pediatric Gastroenterology, Hepatology, and Nutrition. JPGN. 2009; 49: 
498-547.

22. Spinelli C, Bertocchini A, Massimetti M, Ughi C. Muscle Thickness in infants hypertrophic pyloric stenosis. Med. Surg Ped. 2003; 25: 14850.

23. Almaramhy $\mathrm{HH}$, Alshareif $\mathrm{HA}$. Use of atropine sulfate in the treatment of infantile hypertrophic pyloric stenosis. Jour of Tahibah Univ Med Sci. 2013; 8: 173-77.

24. Kawahara H, Takama Y, Yoshida H, Nakai H, Okuyama H, Kubota A et al. Medical treatment of infantile hypertrophic pyloric stenosis: Should we always slice the olive?. Journ of Ped Surg. 200;40: 1848-51.

25. Georgoula C, Gardiner M. Pyloric stenosis a 100 years after Ramstedt. Arch Dis Child. 1997: 97; 741-45.

26. Bizoochi A, Metz D. Treating pyloric stenosis medically in a Resource poor setting. Ann Pediatr Child Health; 4: 1-4.

27. Cappielo CD, Strauch E. A Rare case of recurrent hypertrophic pyloric stenosis. J Ped Surg Case Reports 2. 2014; 519-21.

28. Clayden M, Lissauer T, Graham. Illustrated textbook of paediatrics 3rd ed. Edinburgh; New York: Mosby/Elsevier.2013: 207-208.

29. Tiao MM, Tsai SS, Kuo HW, Yang CY. Epidemiological features of infantile hypertrophic pyloric stenosis in Taiwan: a national study 1996-2004. J Gastroenterol Hepatol. 2011 Jan. 26(1): 78-81.

30. Hall NJ, Van Der Zee J, Tan HL, Pierro A. Metaanalysis of laparoscopic versus open pyloromyotomy. Annals of Surgery 2004; 240(5): 774-8.

31. Aspelund G and Langer JC. Current management of hypertrophic pyloric stenosis. Seminars in pediatric surgery. Elsevier, 2007; 27-33.
32. Meissner PE, EngelmannG, Troeger J, et al. Conservative treatment of infantilehypertrophic pyloric stenosis with intravenous atropine sulfate does not replace pyloromyotomy. Pediatr Surg Int 2006; 22(12): $1021-4$.

33. Costanzo CM, Vinocur $\mathrm{C}$ and Berman L. Prematurity affects age of presentation of pyloric stenosis. Clinical pediatrics. 2017; 56: 127-31. 